\title{
Medical Image of the Week: Septated Pleural Effusion
}

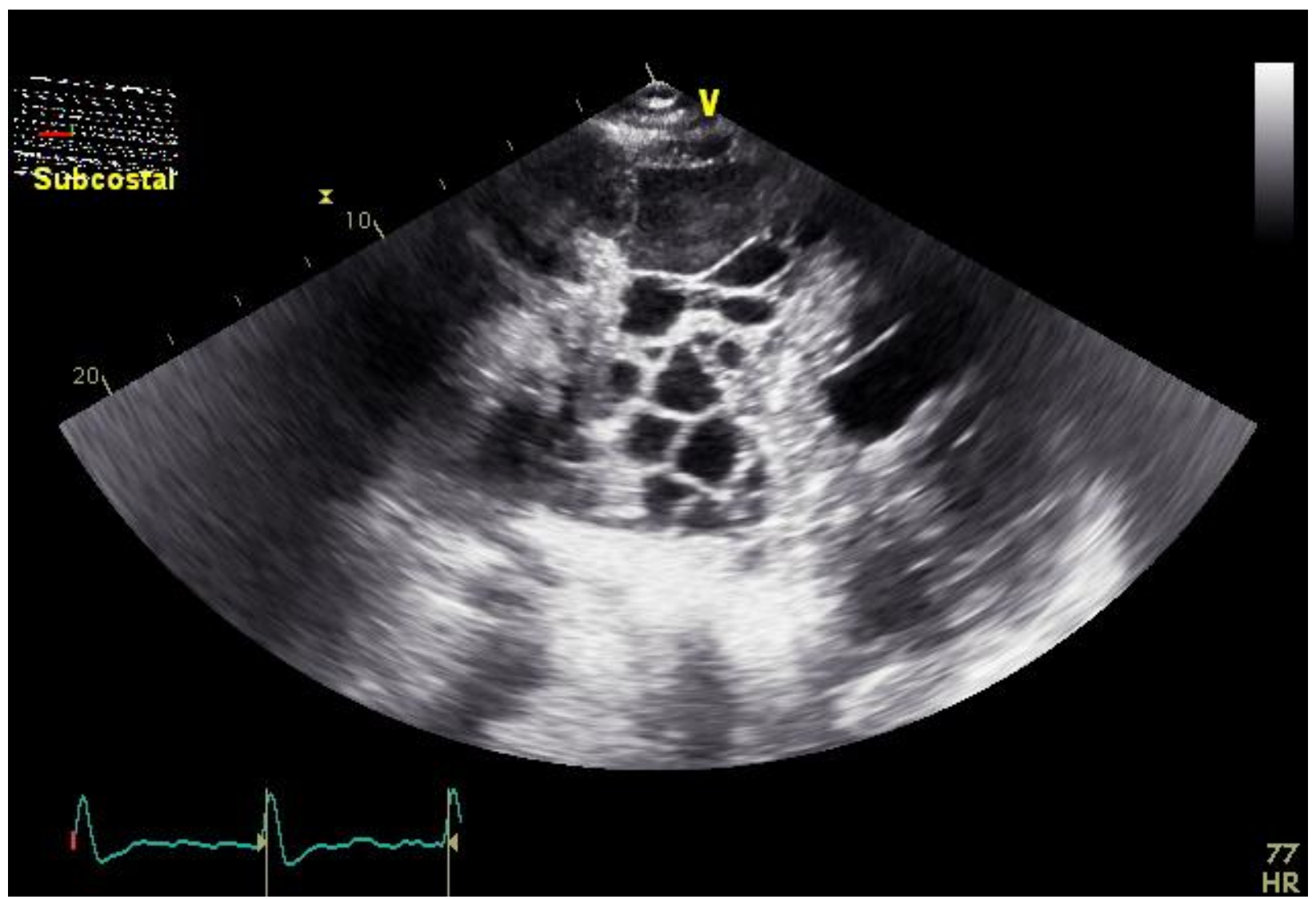

Figure 1. Thoracic ultrasound showing pleural effusion with multiple septations.

An 83 year old man with a history of metastatic malignant melanoma and atrial fibrillation on warfarin was admitted for shortness of breath. He underwent a diagnostic and therapeutic thoracentesis for a large right sided pleural effusion, suspected to be malignancy related. Three days later, he had transferred to the ICU for respiratory distress. An ultrasound of the thorax revealed a large loculated effusion with multiple septations (Figure 1). A large bore chest tube was placed and revealed a hemothorax, which may have been related to the previous thoracentesis.

In an observational study of ultrasound characteristics of pleural effusions, complex septations were more commonly seen in non-malignant effusions than malignant effusions (25.4\% vs. 7.5\%). In non-malignant effusions, the septated pattern was associated with infections, specifically tuberculosis and pneumonia (1).

While metastases in melanoma commonly involve the thoracic cavity, malignant pleural effusions are rare and are seen in about $2 \%$ of cases. In very rare instances, effusions from metastatic melanoma can be black in appearance (2). There has also been a case report of a massive hemothorax related to melanoma implants on the pleura (3). 
Candy Wong, MD ${ }^{1}$; Soyoung Park, MD²; Courtney Walker, DO²; and Laura Meinke, $\mathrm{MD}^{1}$

1

Division of Pulmonary, Allergy, Critical Care, and Sleep, Department of Medicine.

2

Department of Medicine

University of Arizona

Tucson, AZ

\section{References}

1. Bugalho A, Ferreira D, Dias SS, Schuhmann M, Branco JC, Marques Gomes MJ, Eberhardt R. The diagnostic value of transthoracic ultrasonographic features in predicting malignancy in undiagnosed pleural effusions: a prospective observational study. Respiration. 2014;87:270-8. [CrossRef] [PubMed]

2. Liao WC, Chen $\mathrm{CH}$, Tu CY. Black pleural effusion in melanoma. CMAJ. 2010;182(8):E314. [CrossRef] [PubMed]

3. Gibbons JA, Devig PM. Massive hemothorax due to metastatic malignant melanoma. Chest. 1978;73(1):123. [CrossRef] [PubMed] 